\title{
Qualitätssicherung in der Teilereinigung
}

\author{
Mit dem Ziel, den Dialog zwischen Anwendern und Anbietern aus der industriellen Teilereinigung \\ zu fördern, trafen sich am 8. März in Stuttgart 25 Vertreter von Anwendern, Anlagenherstellern und \\ Forschungsinstituten zum Workshop „Qualitätssicherung in der Teilereinigung“.
}

m Einstiegsvortrag erläuterte Professor Lothar Schulze von der Sita Messtechnik seine Intention für den Workshop: der Austausch und die Kooperation zwischen Lieferanten und Anwendern mit dem Ziel, wirtschaftlicher und effektiver zu reinigen. Den Bedarf für mehr Austausch begründete Schulze unter anderem mit den Ergebnissen aus einer Umfrage unter Reinigungsanlagenbetreibern, die einen Mangel an prozessangepasster Messund Prüftechnik und auch einen Mangel an Erfahrungen zur Qualitätssicherung ergab.

Laut Schulze geht es darum, Qualität zu erzeugen statt zu erprüfen und die Sauberkeit von Bauteilen stabil zu sichern. Für die Steuerung des Teileund Informationsflusses sind Leitlinien zur Qualitätssicherung erforderlich. Wesentliche Kriterien dabei sind eine konstante Kontrolle, die Erfassung von Veränderungen sowie ein rechtzeitiges Eingreifen in den Prozess. Erforderlich ist dazu laut Schulze die Aufbereitung und Umsetzung von Erfahrungen, die Entwicklung und Umsetzung von Systemlösungen sowie eine enge Zusammenarbeit zwischen Teileherstellern und Lieferanten.

In der Diskussion berichteten die Workshop-Teilnehmer über ihre Probleme in Sachen Reinigungstechnik sowie ihre Wünsche, Ziele und Erfahrungen. So forderte der Vertreter eines
Institutes, dass mehr und schneller gemessen werden müsse. Ein Anlagenhersteller wies beispielsweise darauf hin, dass am Markt bereits Reinigungsanlagen mit integrierten qualitätssichernden Maßnahmen zur Verfügung stehen.

Die Ergebnisse der Diskussion sollen nun in die weiteren Aktivitäten mit einfließen. So sollen in einem Workshop Ende Juni 2013 in Augsburg unter anderem Lösungsansätze für eine qualitätssichernde Prozessführung erarbeitet werden. Erste Ergebnisse der Arbeitstreffen sollen dann im Rahmen eines eintägigen Qualitätsforums auf der Parts2clean 2013 vorgestellt werden.

$(\mathrm{Ke})$

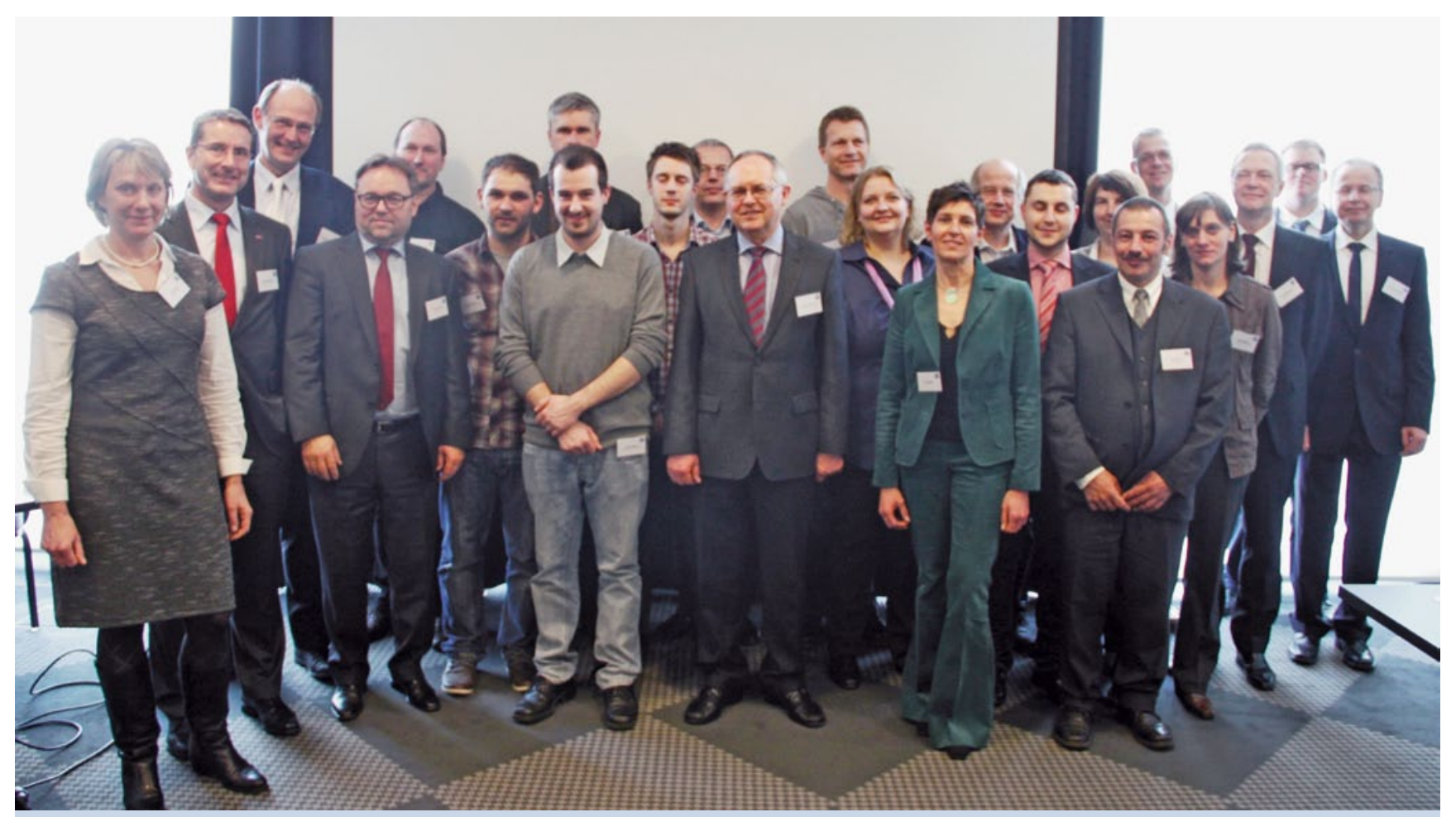

Die 25 Teilnehmer nutzten den Workshop intensiv zum Austausch von Erfahrungen und Informationen 